\title{
Effects of Saikosaponin D on apoptosis genes expression profile of the colon cancer cells HT-29
}

\author{
Min Lu, Haoran Sunlu*, Jing Yang, Liang Wang
}

Department of Anorectal surgery, First Affiliated Hospital of China Medical University, Shenyang, 110001, PR China.

Accepted 30 May, 2013

\begin{abstract}
The present study aims to investigate the change of apoptosis genes expression of HT29 cells induced by Saikosaponin D (SSD), which is the major component of Xiao Chai Hu Tang, the classic Chinese medicine prescriptions. In this study, gene expression profiles of HT29 cells with or without the SSD treatment were obtained by means of using RT ProfilerTMPCR Array Human Apoptosis and quantitative real-time polymerase chain reaction (PCR) and analyzed to detect differential gene expression. According to results of 3- (4,5-dimethylthiazol-2-yl)-2,5-diphenyl tetrazolium bromide (MTT) assay, a final concentration of $10 \mathrm{mg} / \mathrm{L}$ of SSD for $24 \mathrm{~h}$ was used in the SSD group and the growth inhibition rate of HT-29 cells was about 5\%. In SSD treated cells, expression levels of 14 kinds of apoptosis genes changed significantly. Compared with the control group, some apoptosis genes such as DIVA, CASP10, and TRAILR were expressed at much higher levels, while some anti-apoptosis gene such as HIAPI, NAIP, BCL2 were also expressed at much higher levels. SSD induces the apoptosis of HT29 through the apoptosis pathway of TRAIL, TRAIL-R and caspase10 and/or caspase8. And these data could provide targets for the treatment of colon cancer.
\end{abstract}

Key words: Saikosaponin D, colon carcinoma, apoptosis, gene expression.

\section{INTRODUCTION}

Xiao Chai Hu Tang first recorded in the Chinese Ancient medicine book "Febrile Diseases"is widely used in clinical treatment of inflammation, cancer prevention and control, and is a classic Chinese medicine prescription. Saikosaponin is the major component of Xiao Chai $\mathrm{Hu}$ Tang. There have been many studies on anti-tumor effect of the saikosaponin and its extracts by local and foreign scholars, confirming that saikosaponin D (SSD) has the strongest anti-inflammatory effect in the four kinds of of saikosaponin; same as some other saponins drugs with anti-tumor effects. However, the antitumor mechanism of SSD is still unclear (Wang et al., 2006; Zu 2000). It was confirmed that in leukemia, liver cancer, lung cancer and other tumor cells, SSD could induce apoptosis through different mechanisms, such as increasing FASL, FAS, and $B A X$ protein expression, reducing B-cell lymphoma 2 (BCL2), BCL-XL expression, activating poly (ADP) poly- merase (PARP) shear, or cracking inhibitors of apoptosis (IAP) family members XIAP and cIAP-2 among others (Hsua et al., 2004a; 2008; Yu et al.,2008). It was reported that as one of the four kinds of of saikosaponin, saikosaponin A (SSA) could induce apoptosis in colon cancer cells through activation of CASP2 and CASP8 (Kim et al., 2010), so whether SSD is able to induce apoptosis in colon cancer cells and the mechanism of SSD induced apoptosis is still unclear.

In this study, by means of using the apoptosis gene polymerase chain reaction (PCR) microarray and quantitative real-time PCR technology, we screened the SSD-induced differentially expressed apoptosis genes in the colon cancer cells. Here, we found and reported that there were 15 kinds of apoptosis genes whose expression were significantly changed, and these apoptosis genes might play a major role in SSD-induced 
Table 1. Inhibition effects of saikosaponin D on the growth of colon cancer HT-29 cell.

\begin{tabular}{cccc}
\hline Group & \multicolumn{3}{c}{ Inhibition rate (\%) } \\
\cline { 2 - 4 } & $\mathbf{2 4} \mathbf{h}$ & $\mathbf{4 8} \mathbf{~}$ & $\mathbf{7 2} \mathbf{~}$ \\
\hline $0(\mathrm{mg} / \mathrm{L})$ & $0.11 \pm 0.02$ & $0.09 \pm 0.012$ & $0.14 \pm 0.021$ \\
$5(\mathrm{mg} / \mathrm{L})$ & $1.9 \pm 0.14$ & $17.8 \pm 0.24$ & $19.1 \pm 0.21$ \\
$10(\mathrm{mg} / \mathrm{L})$ & $5.0 \pm 0.17$ & $31.2 \pm 0.12$ & $33.4 \pm 0.28$ \\
$20(\mathrm{mg} / \mathrm{L})$ & $9.4 \pm 0.18$ & $42.3 \pm 0.31$ & $44.5 \pm 0.18$ \\
\hline
\end{tabular}

apoptosis of the colon cancer cells. These results laid the foundation for understanding the mechanisms of saikosaponin D-induced apoptosis of colon cancer cells, and could provide targets for the treatment of colon cancer.

\section{MATERIALS AND METHODS}

\section{Materials}

Saikosaponin D was purchased from Chinese medicine and biological products Institution (Beijing, China); Colon cancer cell line HT-29 cells were purchased from Shanghai Institute of Cell Biochemistry Life Sciences (Shanghai, China). Cell culture, RNA purification and reverse transcription reagents were mainly purchased from Invitrogen company and TakaRa company; RT ProfilerTM human apoptotic gene PCR microarray (PAHS-012A) were purchased from SABiosciences company.

\section{Methods}

\section{Cell growth inhibition assay}

Cells were seeded into 96-well plates $\left(5 \times 10^{3}\right.$ cells/well) for $12 \mathrm{~h}$, followed by treatment with various concentrations of saikosaponin D. Cell viability was determined using the 3-[4, 5-dimethylthiazol-2yl]-2, 5-diphenyltetrazolium bromide (MTT) assay. In brief, $15 \mu \mathrm{l}(5$ $\mathrm{mg} / \mathrm{ml}$ ) MTT working solution was added to per well and then incubated at $37^{\circ} \mathrm{C}$ for $4 \mathrm{~h}$. Then the supernatant was removed and $150 \mu \mathrm{l}$ of dimethylsulphoxide (DMSO) was added to each well to dissolve the crystals. The absorbance of each well at $570 \mathrm{~nm}$ was measured under an ELx 808 Universal Microplate Reader (BIOTEK, INC). Data were expressed as the percentage of cellular viability relative to the control culture (assuming 100\%) in the present study.

\section{Cells drug treatment and RNA purification identification}

The same number of HT-29 cells were inoculated in the cell culture dish with an equivalent diameter of $10 \mathrm{~cm}$. After $24 \mathrm{~h}$, cells were treated with $0 \mathrm{mg} / \mathrm{L} \mathrm{SSD}$ (control group) or $10 \mathrm{mg} / \mathrm{L}$ (experimental group), and for another $24 \mathrm{~h}$, the cells were collected. Total RNA of the cells sample was extracted with Trizol reagent (Gibco, USA) as described by the manufacturer. RNA was purified using RNeasy $\AA$ MinElute ${ }^{\mathrm{TM}}$ purification kit (Qiagen); quality, concentration and purity of RNA were measured using the agarose gel electrophoresis method and the UV absorption. RT-PCR was performed using SuperScript. III Reverse Transcriptase (invitrogen). PCR was performed for 30 cycles in $25 \mu$ of reaction mixture.

\section{Apoptosis gene PCR microarray assay}

$10 \mu \mathrm{l} \mathrm{cDNA}$ and SuperArray PCR master mix (Cat. No. PA-112) premixed solution was added to each well of PCR microarray. Realtime PCR procedure was set as follows: Denaturation at $95^{\circ} \mathrm{C}$ for $10 \mathrm{~min}$, amplification of 40 cycles at $95^{\circ} \mathrm{C}$ for $15 \mathrm{~s}$ and $60^{\circ} \mathrm{C}$ for 1 min. After collecting the fluorescence, the melting curve was analysed.

Data were analyzed by $\Delta \Delta \mathrm{Ct}$ method, and the fluorescence threshold was set to 0.15 . $\Delta \mathrm{Ct}$ was the mean number of the threshold cycle number of each gene subtracting the threshold cycle of housekeeping gene B2M, HPRT1, GAPDH, ACTB.Gene $\Delta \triangle \mathrm{Ct}$ was the $\Delta \mathrm{Ct}$ of the SSD group minus the control group $\Delta \mathrm{Ct}$. The differences of each gene expression were calculated with 2$\triangle \triangle \mathrm{Ct}$ calculation of DHA and control groups (Livak and Schmittgen, 2001). PCR microarray experiments technical services were provided by the Kangcheng Sheng Bio-Engineering Co., Ltd. (Shanghai, China).

\section{RESULTS AND DISCUSSION}

\section{Identification of RNA samples from Saikosaponin D- treated Colon cancer cells}

According to results of MTT assay (Table 1), a final concentration of $10 \mathrm{mg} / \mathrm{L}$ of SSD for $24 \mathrm{~h}$ was used in the SSD group, and the growth inhibition rate of HT-29 cells was about $5 \%$, consistent with the results reported by Hsua et al. (2004b) in non-small lung cancer cells. The UV absorption ratio Abs260/Abs280 reflecting the purity of RNA samples from SSD and control groups were 2.00 and 2.02, respectively. As shown in Figure 1, two clear 28S, 18S ribosomal RNA bands and one RNA band with a little spread and low molecular weight were observed in both the SSD and control groups. And above the 28S ribosomal RNA band, the diffusion of high molecular weight substances or belt usually resulting from DNA contamination was not observed.

\section{The analyses of SSD-induced apoptosis genes differential expression profile in HT-29 cells}

As shown in Figure 2a, the column height of threedimensional histogram meant multiples of differentially expressed genes, $2^{\wedge}$ - $\Delta$ Ct ratio of gene mRNA expression from the SSD group to that from the control group. The measured genes distribution is shown in Figure $2 b$. 


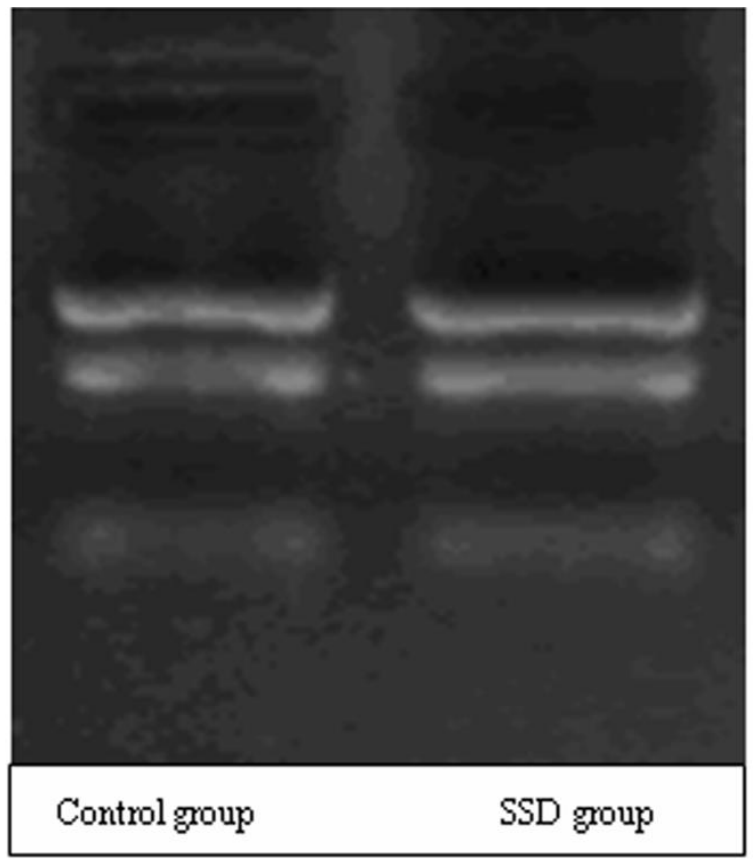

Figure 1. Purity identification of RNA samples by denatured agarose gel electrophoresis (left: control group; right: SSD group).

A

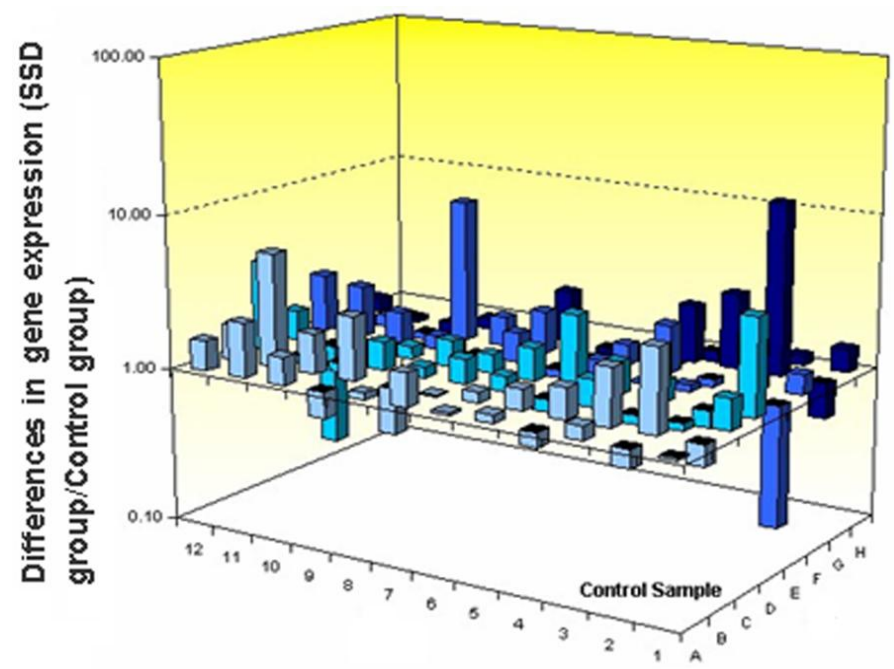

\begin{tabular}{|c|c|c|c|c|c|c|c|c|c|c|c|}
\hline ABLL & AKT1 1 & APAF 1 & BAD & BAG1 & BACB & BACA & BAK1 & Bax & BC.10 & ecL2 & BCLLA: \\
\hline$A 01$ & $\mathrm{~A}_{02}$ & $\mathrm{AOS}_{3}$ & $A 04$ & AOS & AOS & $A 07$ & A0s & A09 & A10 & A11 & A12 \\
\hline BCL2L1 & BC.2L10 & BCLLLL11 & BC.2L2 & BCLAFI & BFAR & 850 & $81 x$ & BtRC1 & BIRC2 & BIRC3 & BIRC4 \\
\hline B01 & B02 & 803 & 804 & Bo5 & 806 & B07 & B08 & $B 09$ & B10 & B11 & B12 \\
\hline BARC6 & BIRCB & BNIP1 & BNIP2 & BNIP3 & BNIP3L & BRAF & CARDA & CARDS & CARDS & CASP1 & CASP:O \\
\hline$\infty 1$ & $\infty 2$ & $\mathrm{CO} 3$ & $\mathrm{CO} 4$ & $\cos$ & $\cos$ & $\mathrm{CO}$ & $\cos$ & $\cos$ & C10 & $C_{11}$ & $\mathrm{C}_{12}$ \\
\hline CASP14 & CASP2 2 & CASP3 & CASP4 & CASPS & CASP6 & CASP7 & CASPB & CAsp9 & $\mathrm{CD} 40$ & COAOLG & CRAR \\
\hline D01 & $\infty 2$ & $\infty 3$ & Do4 & Dos & DO6 & D07 & Dos & $D 09$ & 010 & D11 & 012 \\
\hline
\end{tabular}

Figure 2. The SSD-induced apoptosis genes differential expression profiles in colon cancer cell line HT-29 cells. A, SSD-induced apoptosis genes differential expression; b, PCR microarray gene distribution. 
Table 2. Part of significantly up-regulated apoptosis-related genes induced by SSD in HT-29 cells.

\begin{tabular}{|c|c|c|c|c|c|c|}
\hline \multirow{2}{*}{ Symbol } & \multirow{2}{*}{ Well } & \multicolumn{2}{|c|}{$2^{\wedge}-\Delta C t$} & \multirow{2}{*}{$\begin{array}{c}\text { Fold change } \\
\text { SSD /control } \\
\text { group }\end{array}$} & \multirow{2}{*}{$\begin{array}{c}\begin{array}{c}\text { Fold up- or down- } \\
\text { regulation }\end{array} \\
\text { SSD /control } \\
\text { group }\end{array}$} & \multirow{2}{*}{$\begin{array}{l}\text { Open gene table in web browser } \\
\text { Description }\end{array}$} \\
\hline & & $\begin{array}{l}\text { SSD } \\
\text { group }\end{array}$ & $\begin{array}{l}\text { Control } \\
\text { group }\end{array}$ & & & \\
\hline BCL2 & A11 & $8.90 \mathrm{E}-04$ & 3.99E-04 & 2.23 & 2.23 & B-cell CLL/lymphoma 2 \\
\hline BCL2L10/DIVA & B02 & 4.35E-05 & $1.25 \mathrm{E}-05$ & 3.48 & 3.48 & BCL2-like 10 (apoptosis facilitator) \\
\hline BCL2L11/BAM & B03 & $1.82 \mathrm{E}-02$ & 7.82E-03 & 2.33 & 2.33 & BCL2-like 11 (apoptosis facilitator) \\
\hline NAIP & B09 & 4.13E-03 & $1.57 \mathrm{E}-03$ & 2.63 & 2.63 & NLR family, apoptosis inhibitory protein \\
\hline HIAP1/BIRC3 & B11 & $1.12 \mathrm{E}-03$ & $2.02 \mathrm{E}-04$ & 5.54 & 5.54 & Baculoviral IAP repeat-containing 3 \\
\hline CASP10 & $\mathrm{C} 12$ & 5.37E-04 & 1.37E-04 & 3.92 & 3.92 & $\begin{array}{l}\text { Caspase } 10 \text {, apoptosis-related cysteine } \\
\text { peptidase }\end{array}$ \\
\hline IGF1R & E11 & $1.14 \mathrm{E}-02$ & $5.25 \mathrm{E}-03$ & 2.17 & 2.17 & Insulin-like growth factor 1 receptor \\
\hline LTA/TNFB & E12 & $1.01 \mathrm{E}-04$ & 4.19E-05 & 2.41 & 2.41 & $\begin{array}{l}\text { Lymphotoxin alpha (TNF superfamily, } \\
\text { member 1) }\end{array}$ \\
\hline MCL1 & F02 & $9.35 \mathrm{E}-02$ & $4.12 \mathrm{E}-02$ & 2.27 & 2.27 & $\begin{array}{l}\text { Myeloid cell leukemia sequence } 1 \\
\text { (BCL2-related) }\end{array}$ \\
\hline PYCARD & F04 & $2.71 \mathrm{E}-05$ & $1.31 \mathrm{E}-05$ & 2.07 & 2.07 & PYD and CARD domain containing \\
\hline TNFRSF9/CD137 & G02 & 3.73E-05 & $2.87 E-06$ & 12.98 & 12.98 & $\begin{array}{l}\text { Tumor necrosis factor receptor } \\
\text { superfamily, member } 9\end{array}$ \\
\hline TNFSF10/TRAIL & G03 & 5.09E-05 & $1.62 E-05$ & 3.14 & 3.14 & $\begin{array}{l}\text { Tumor necrosis factor (ligand) } \\
\text { superfamily, member } 10\end{array}$ \\
\hline CD70 & G04 & 8.33E-04 & 3.56E-04 & 2.34 & 2.34 & CD70 molecule \\
\hline TP53BP2 & G07 & $6.07 \mathrm{E}-02$ & $2.72 \mathrm{E}-02$ & 2.23 & 2.23 & Tumor protein p53 binding protein, 2 \\
\hline CIDEA & E01 & $1.30 \mathrm{E}-05$ & 3.72E-05 & 0.35 & -2.90 & Cell death-inducing DFFA-like effector a \\
\hline
\end{tabular}

These results suggest that SSD could induce 14 kinds of significantly up-regulated apoptosis genes in colon cancer cell line HT-29, and the differences multiples of these genes were higher than 2 (Table 2). Interestingly, the gene CIDEA expression level was significantly reduced, but the difference multiple was less than 0.5 , maybe because this gene expression level in both the SSD group and control group was low, the reduced significance in this experiment was not statistically significant.
SSD induced significantly up-regulated expression of 14 kinds of apoptosis genes in HT-29 cells, including pro-apoptotic genes TRAIL, CASP10, TNFB, BAM and DIVA, and anti-apoptotic genes BCL2, HIAP1, NAIP and so on. Meanwhile, there were also some genes, which were up-regulated but increased in less than 2-fold expression, including CASP8 (1.48), CASP9 (1.23), CASP3 (1.39) and TRAIL receptor gene TNFRSF10A (1.88), TNFRSF10B (1.55). These results suggest that SSD triggered apoptosis in HT-29 cells by the
TRAIL death receptor pathway. In the TRAILinduced apoptosis, CASP10 may replace CASP8 or synergy with CASP8 from the classic death receptor pathway (Kischkel et al., 2001). CD137, which has a significant increase in SSD-treated cells, might play an anti-tumor role by regulating the immune responses of tumor cells (Ju et al., 2003).

TNFB has been found to induce the apoptosis by the mitochondrial pathway, although the molecular mechanisms were still unclear. In HT-29 
cells, SSD induced increased expression of TNFB possibly resulted in the cells apoptotic by the mitochondrial pathway. And moreover, the pro-apoptotic BCL2 family members BAM and DIVA were significantly up-regulated in SSD-treated cells and this suggested that the mitochondrial pathway played an important role in SSDtreated cells apoptosis. In addition, up-regulated TNFB heterotrimer binds with receptors, and may in turn recruit TRAF2, TRAF3 and CIAP1, and the BIR1 domain of clAP1 were removed in this process, so that CASP9, CASP7, and CASP3 activity were activated (Kuai et al., 2003). In short, these data suggest SSD induced the apoptosis of HT29 through the apoptosis pathway of TRAIL, TRAIL-R and caspase 10 and/or caspase8, and could provide targets for the treatment of colon cancer.

\section{ACKNOWLEDGEMENTS}

This work was supported by the grant from Science and Technology Program of Liaoning Province Science and Technology Agency (NO. 2009225008-9).

\section{ABBREVIATIONS}

SSD, Saikosaponin D; PARP, poly(ADP)polymerase; BCL2, B-cell lymphoma 2; IAP, inhibitors of apoptosis; SSA, saikosaponin A; PCR, polymerase chain reaction; MTT, 3-[4, 5-dimethylthiazol-2-yl]-2, 5-diphenyltetrazolium bromide; DMSO, dimethylsulphoxide.

\section{REFERENCES}

Hsua YL, Kuob PL, Chiangc LC, Lin CC (2004a). Involvement of p53, nuclear factor $\mathrm{KB}$ and Fas/Fas ligand in induction of apoptosis and cell cycle arrest by saikosaponin $D$ in human hepatoma cell lines.Cancer Lett. 213(2):213-221

Hsua YL, Kuo PL, Lin CC (2004b). The proliferative inhibition and apoptotic mechanism of Saikosaponin $D$ in human non-small cell lung cancer A549 cells. Life Science. 75(10): 1231-1242

Ju SW, Zhang XG (2003). Costimulatory molecule 4-1BB and its ligand 4-1BB Ligand (4-1BBL) and tumor immunity. Chinese Journal of Immunology. 19: 582-584

Kim BM, Hong SH (2010). Sequential caspase-2 and caspase-8 activation is essential for saikosaponin A-induced apoptosis of human colon carcinama cell lines. Apoptosis. Epub ahead of print.

Kuai J, Nickbarg E, Wooters J, Qiu Y, Wang J, Lin LL (2003). Endogenous association of TRAF2, TRAF3, clAP1, and Smac with lymphotoxin beta receptor reveals a novel mechanism of apoptosis. $J$ Biol Chem. 278(16): 14363-14369

Kischkel FC, Lawrence DA, Tinel A, LeBlanc H, Virmani A, Schow $P$, Gazdar A, Blenis J, Arnott D, Ashkenazi A (2001). Death receptor recruitment of endogenous caspase-10 and apoptosis initiation in the absence of Caspase-8. J Biol Chem. 276(49): 46639-46646

Livak KJ, Schmittgen TD (2001). Analysis of relative gene expression data using real-time quantitative PCR and the 2 (-delta delta $C(T)$ ) method. Methods. 25(4): 402-408

Wang YL, He SX, Luo JY (2006). Research progress in the Anti-tumor mechanism of saikosaponin research. Journal of Medicine. 4 (1): 98 100

Yu HL, Ma WL, Zheng WL (2008).Differential screening of Saikosaponin D- induced apoptosis genes in K562 cells. Shandong Medicine. 48 (26): 895-897

Zu SM (2000).Japanese herbal medicine for protection against hepatic fibrosis and carcinoma. J Gastroenterol Hepatol. 15: D84-90. 